\title{
Conservação da Floresta com Araucária no Extremo Sul do Brasil
}

\section{Conservation of Araucaria Forests in the Extreme South of Brazil}

\author{
Marcos Bergmann Carlucci1,*, João André Jarenkow², \\ Leandro da Silva Duarte ${ }^{1,3}$ \& Valério De Patta Pillar ${ }^{1,3}$
}

\author{
${ }^{1}$ Programa de Pós-graduação em Ecologia, Universidade Federal do Rio Grande do Sul - UFRGS \\ ${ }^{2}$ Departamento de Botânica, Universidade Federal do Rio Grande do Sul - UFRGS \\ ${ }^{3}$ Departamento de Ecologia, Universidade Federal do Rio Grande do Sul - UFRGS
}

A Floresta com Araucária, ocorrente nas grandes altitudes do sul do Brasil, é um dos ecossistemas florestais mais ameaçados do país. Estima-se que apenas cerca de 3\% (Bauermann \& Behling 2009) a 13\% (Ribeiro et al. 2009) da cobertura original da formação tenham restado como resultado da intensa pressão exploratória que sofreu ao longo de várias décadas (Koch \& Corrêa 2002). O motivo de tal devastação deve-se ao fato de Araucaria angustifolia (Bertol.) Kuntze e algumas espécies associadas terem representado a principal fonte madeireira do Brasil durante grande parte do século XX (Hueck 1972; Koch \& Corrêa 2002). A Floresta com Araucária tem sido amplamente considerada como componente da Floresta Atlântica (Oliveira \& Fontes 2000), apesar de características únicas quanto à sua fisionomia e sua composição florística, além de peculiaridades do clima e do relevo onde ocorre. Embora tenha sofrido uma devastação proporcionalmente tão grande ou maior do que a da Floresta Atlântica stricto sensu, surpreendentemente, algumas áreas de ocorrência de Floresta com Araucária ainda são tema de debate no meio acadêmico.

A Floresta com Araucária distribui-se no sul do Brasil, em altitudes médias de 600 a 800 m no Planalto Sul-Brasileiro, sendo que em algumas poucas áreas atinge mais de $1000 \mathrm{~m}$ (Rambo 1956; Hueck 1972). A formação é encontrada nos Estados do Rio Grande do Sul, Santa Catarina e Paraná, onde ocorriam as áreas originais mais extensas e contínuas, e nos Estados de São Paulo, do Rio de Janeiro e de Minas Gerais, na província de Misiones, na Argentina, e no Paraguai, em

\footnotetext{
${ }^{*}$ Send correspondence to: Marcos Bergmann Carlucci Programa de Pós-graduação em Ecologia,

Universidade Federal do Rio Grande do Sul - UFRGS, Av. Bento Gonçalves, 9500, CP 15007, CEP 91501-970, Porto Alegre, RS, Brasil

E-mail: marcos.carlucci@gmail.com
}

manchas menores e isoladas (Hueck 1972; Reitz et al. 1983). Os limites geográficos da Floresta com Araucária estariam, ao norte, no Rio Doce, em Minas Gerais (cerca de $18^{\circ} \mathrm{S}$ de latitude), ao leste, nos divisores de água da Serra do Mar e no limite das escarpas do Planalto Sul-Brasileiro, e ao oeste, em Misiones, na Argentina (Hueck 1972). Vários trabalhos apontam que a formação tem seu limite austral no Planalto Sul-Brasileiro (Rambo 1956, 1958; Hueck 1972), a cerca de $29.5^{\circ} \mathrm{S}$ de latitude, enquanto outros sustentam a ocorrência disjunta de núcleos de Floresta com Araucária em latitudes maiores, na Serra do Sudeste, no Estado do Rio Grande do Sul (Hueck 1953; Reitz et al. 1983).

A Serra do Sudeste é um complexo geomorfológico localizado no extremo sul do Brasil e em parte da República do Uruguai (Kaul 1990). No Rio Grande do Sul estende-se entre as latitudes $30^{\circ} \mathrm{S}$ e $32^{\circ} \mathrm{S}$, onde alcança altitudes de até $550 \mathrm{~m}$. A Serra do Sudeste é também chamada de Escudo Sul-Riograndense ou Escudo Cristalino, devido à sua composição geológica ser principalmente de granito, embora gnaisse e arenito conglomerático também sejam encontrados na região (Rambo 1956; Dutra \& Stranz 2003). Sua vegetação consiste em um mosaico relativamente bem conservado de campos manejados principalmente com gado bovino e ovino e de florestas estacionais ocorrentes em manchas insulares, em galeria ou de maneira mais contínua nas encostas do relevo. Algo instigante na Serra do Sudeste é a presença das coníferas A. angustifolia e Podocarpus lambertii Klotzsch ex Endl. em várias manchas de Floresta Estacional, onde atingem a latitude $31.5^{\circ} \mathrm{S}$ (Backes 1999). Essas duas espécies são amplamente reconhecidas como características da Floresta com Araucária do Planalto Sul-Brasileiro, onde ocorrem até a latitude $29.5^{\circ} \mathrm{S}$. O limite austral da Floresta com Araucária é um assunto que instiga os pesquisadores há pelo menos um século. Lindman (1906) observou indivíduos de A. angustifolia tanto isolados em 
meio ao campo quanto crescendo em florestas de encosta na Serra do Sudeste, mas parecia ter dúvida quanto ao caráter nativo da espécie na região.

$\mathrm{Na}$ discussão sobre o limite austral da distribuição da Floresta com Araucária, de um lado, Rambo (1956, 1958) cita que não existem pinheiros nativos ao sul do paralelo $30^{\circ} \mathrm{S}$. Outras obras importantes como o "Inventário Florestal do Pinheiro no Sul do Brasil” (IBDF 1978) e "As florestas da América do Sul" (Hueck 1972) também desconsideram a ocorrência da formação em latitudes maiores do que $30^{\circ} \mathrm{S}$. Em contraponto, Reitz et al. (1983) citam a ocorrência de A. angustifolia ao sul do rio Jacuí, na Serra do Sudeste, formando "agrupamentos nativos" nos municípios de Santana da Boa Vista, Encruzilhada do Sul, Dom Feliciano, São Lourenço do Sul e Canguçu. Em Canguçu, os autores afirmam ter havido "o maior núcleo de pinhal do Escudo Rio-Grandense”, o qual teria aproximadamente 8000 ha. Portanto, Reitz et al. (1983) consideram que o limite sul da formação Floresta com Araucária está na Serra do Sudeste (especificamente em Canguçu), a cerca de $31^{\circ}$ de latitude Sul, contrariando o que dizem muitos trabalhos sobre o tema. O Inventário Florestal Nacional de florestas nativas no Rio Grande do Sul (IBDF 1983) considera ainda a ocorrência de "pequenos pinhais nativos" nos municípios de Caçapava do Sul e Piratini, também localizados na região. Backes $(1988,1999)$ bem como Dutra \& Stranz (2003) entram em consonância com Reitz et al. (1983), indicando que os núcleos de Floresta com Araucária ocorrentes na Serra do Sudeste são pequenos mas fitogeograficamente importantes. Um dos mapas de distribuição de Floresta com Araucária mais amplamente utilizado até os dias de hoje foi elaborado pelo importante pesquisador alemão Kurt Hueck. Algo interessante é o fato de Hueck aparentemente ter mudado de opinião quanto ao limite sul da distribuição da Floresta com Araucária entre as décadas de 1950 e 1970 . Primeiramente, o autor considera que na Serra do Sudeste "se encontram florestas de araucárias de pequenas dimensões" e destaca em seu mapa quatro núcleos da formação na região (Hueck 1953); posteriormente, o autor afirma que "ao sul do Jacuí existem araucárias isoladas sem formar matas contínuas” e retira do mapa os núcleos (Hueck 1972). O motivo pelo qual o autor alterou seu consagrado mapa permanece desconhecido.

Recentemente, visitamos algumas localidades da Serra do Sudeste apresentando florestas com A. angustifolia a fim de realizar estudos sobre a organização de comunidades arbóreas em expansão sobre campos (Carlucci 2011). Uma visita foi feita em 2009 ao interior do município de Canguçu-RS (cerca de $31.2^{\circ} \mathrm{S}, 52.5^{\circ} \mathrm{O}$ ), onde encontramos pequenos fragmentos florestais com dossel dominado por A. angustifolia, isolados em uma matriz de lavouras e pastagens artificiais. Avaliando os relatos de moradores locais e a localização dos fragmentos, a área se adéqua ao que fora o grande núcleo citado por Reitz et al. (1983). Tanto o aspecto da paisagem local quanto o depoimento dos moradores denunciam o grande desmatamento que a maior mancha de Floresta com Araucária no seu limite austral sofreu há algumas décadas. Em outros locais como em Santana da Boa Vista-RS (cerca de $30.8^{\circ} \mathrm{S}, 53.1^{\circ} \mathrm{O}$ ), A. angustifolia e P. lambertii estão entre as árvores mais evidentes na paisagem, dominando os dosséis da maioria das manchas florestais em mosaico com campo nativo, onde pelo menos outras 74 espécies de angiospermas arbóreas também estão presentes (Carlucci 2011).

Em diversas excursões à Serra do Sudeste (incluindo também os municípios de Encruzilhada do Sul e Herval), encontramos várias espécies arbóreas típicas da Floresta com Araucária do Planalto além de A. angustifolia e P. lambertii. São elas: Acca sellowiana (O.Berg) Burret, Berberis laurina Thunb., Cinnamomum amoenum (Nees) Kosterm., Dasyphyllum spinescens (Less.) Cabrera, Drimys brasiliensis Miers, Ilex dumosa Reissek, Ilex paraguariensis A. St.-Hil., Lamanonia ternata Vell. e Quillaja brasiliensis Mart.. Entretanto, nem sempre essas espécies são encontradas em associação com $A$. angustifolia como no Planalto, como no caso de D. brasiliensis e L. ternata. De qualquer forma, aparentemente a única característica que une a Floresta com Araucária é a presença de A. angustifolia e de P. lambertii, já que ao longo do gradiente latitudinal dessa formação florestal sua composição florística varia consideravelmente (Duarte et al. 2009).

A grande questão sobre o limite sul da distribuição de A. angustifolia é que, caso as áreas da Serra do Sudeste sejam consideradas nativas - e acreditamos que realmente são -, haveria uma ocorrência disjunta da espécie e, talvez, do tipo vegetacional Floresta com Araucária. Em outras palavras, a espécie e a formação ocorreriam do norte, desde os núcleos pequenos e esparsos da Serra do Mar e da província de Misiones, passando pelas áreas maiores e mais contínuas do Paraná, de Santa Catarina e do Rio Grande do Sul, até a borda meridional do Planalto Sul-Brasileiro (ocorrência amplamente aceita pela comunidade científica), até seu verdadeiro limite sul, os núcleos da Serra do Sudeste no Rio Grande do Sul (separados do restante da área de ocorrência pela Depressão Central gaúcha). Esse tema é especialmente importante no que concerne a uma possível migração de A. angustifolia ou mesmo da flora típica da formação Floresta com Araucária rumo ao sul, ou alternativamente a uma possível evidência remanescente de que a espécie tenha ocorrido continuamente até essas latitudes, talvez há centenas de milhares de anos. O fim dessas divergências, entretanto, provavelmente só seja alcançado através de estudos paleopolínicos e genéticos. Mesmo que A. angustifolia tenha sido introduzida na Serra do Sudeste por humanos há centenas ou milhares de anos, deve-se levar em conta que, mesmo em grande parte do Planalto Sul-Brasileiro, grupos indígenas possivelmente tenham influenciado a dispersão e migração da espécie rumo ao sul (Bitencourt \& Krauspenhar 2006).

Finalmente, destacamos o fato de no Brasil, onde parte considerável da biodiversidade permanece desconhecida, frequentemente desconhecer-se mesmo a distribuição da 
biodiversidade que se presume como conhecida. Dado o déficit de informação científica sobre nossa biodiversidade em termos gerais, esforços conservacionistas devem ser baseados no princípio da precaução em grande parte dos casos no Brasil. Assim, as manchas florestais com Araucaria e Podocarpus da Serra do Sudeste devem ser protegidas desde já, visto que seu desconhecimento até mesmo por grande parte da comunidade científica tem facilitado a negligência de sua conservação.

\section{Agradecimentos}

Agradecemos à Prof Tânia Lindner Dutra por ter indicado áreas bem conservadas de Floresta com Araucária na Serra do Sudeste. As excursões a campo foram financiadas com recursos do CNPq (479083/2008-8) e da CAPES (PROF). M.B.C. recebeu bolsa de mestrado da CAPES e V.D.P. recebeu bolsa de produtividade do $\mathrm{CNPq}$ (306573/2009-1).

\section{Referências}

Backes A, 1988. Condicionamento climático e distribuição geográfica de Araucaria angustifolia (Bertol.) Kuntze no Brasil. Pesquisas, Botânica, 39:5-39.

Backes A, 1999. Condicionamento climático e distribuição geográfica de Araucaria angustifolia (Bertol.) Kuntze no Brasil - II. Pesquisas, Botânica, 49:31-51.

Bauermann SG \& Behling H, 2009. Dinâmica paleovegetacional da Floresta com Araucária a partir do final do Pleistoceno: o que mostra a palinologia. In: Fonseca CR et al., editores. Floresta com Araucária: ecologia, conservação e desenvolvimento sustentável. Ribeirão Preto: Holos. p. 35-38.

Bitencourt ALV \& Krauspenhar PM, 2006. Possible prehistoric anthropogenic effect on Araucaria angustifolia (Bertol.) O. Kuntze expansion during the late holocene. Revista Brasileira de Paleontologia, 9:109-116. http://dx.doi.org/10.4072/ rbp.2006.1.12

Carlucci MB, 2011. Padrões funcionais de organização de árvores juvenis em manchas florestais na Serra do Sudeste do Rio Grande do Sul. [Dissertação]. Porto Alegre: Universidade Federal do Rio Grande do Sul.

Duarte LD, Carlucci MB \& Pillar VD, 2009. Macroecological analyses reveal historical factors influencing seed dispersal strategies in Brazilian Araucaria forests. Global
Ecology and Biogeography, 18:314-326. http://dx.doi. org/10.1111/j.1466-8238.2009.00448.x

Dutra TL \& Stranz A, 2003. História das Araucariaceae: a contribuição dos fósseis para o entendimento das adaptações modernas da família no Hemisfério Sul, com vistas a seu manejo e conservação. In: Ronchi LH \& Coelho OGW, editores. Tecnologia diagnóstico e planejamento ambiental. São Leopoldo: UNISINOS. p. 293-351.

Hueck K, 1953. Distribuição e habitat natural do Pinheiro do Paraná (Araucaria angustifolia). Boletim da Faculdade de Filosofia, Ciências e Letras da Universidade de São Paulo, Botânica, 10(156):5-24.

Hueck K, 1972. As florestas da América do Sul: ecologia, composição e importância econômica. São Paulo: Polígono.

Instituto Brasileiro de Desenvolvimento Florestal - IBDF, 1978. Inventário florestal do pinheiro no sul do Brasil. Curitiba: FUPEF/Instituto Brasileiro de Desenvolvimento Florestal.

Instituto Brasileiro de Desenvolvimento Florestal - IBDF, 1983. Inventário Florestal Nacional - florestas nativas, Rio Grande do Sul. Brasília: Instituto Brasileiro de Desenvolvimento Florestal.

Kaul PFT, 1990. Geologia. In: Instituto Brasileiro de Geografia e Estatística - IBGE, editor. Geografia do Brasil. Rio de Janeiro: Instituto Brasileiro de Geografia e Estatística. p. 29-54.

Koch Z \& Corrêa MC, 2002. Araucária: a floresta do Brasil meridional. Curitiba: Olhar Brasileiro.

Lindman CAM, 1906. A vegetação no Rio Grande do Sul. Porto Alegre: Universal.

Oliveira AT \& Fontes MAL, 2000. Patterns of floristic differentiation among Atlantic forests in southeastern Brazil and the influence of climate. Biotropica, 32:793-810.

Rambo B, 1956. A fisionomia do Rio Grande do Sul. Porto Alegre: Selbach.

Rambo B, 1958. A floresta riograndense. Agronomia Sulriograndense, 3:1-15.

Reitz R, Klein RM \& Reis A, 1983. Projeto madeira do Rio Grande do Sul. Sellowia, 34-35:1-525.

Ribeiro MC et al., 2009. The Brazilian Atlantic Forest: how much is left, and how is the remaining forest distributed? Implications for conservation. Biological Conservation, 142:1141-1153. http://dx.doi.org/10.1016/j. biocon.2009.02.021 
